\title{
Brief communication: On direct impact probability of landslides on vehicles
}

\author{
Pierrick Nicolet $^{1 \text {,a }}$, Michel Jaboyedoff ${ }^{1}$, Catherine Cloutier $^{2}$, Giovanni B. Crosta $^{3}$, and Sébastien Lévy ${ }^{4}$ \\ ${ }^{1}$ Institute of Earth Sciences, Faculty of Geosciences and Environment, University of Lausanne, Lausanne, Switzerland \\ ${ }^{2}$ Laboratoire d'études sur les risques naturels, Département de géologie et de génie géologique, Université Laval, \\ Québec, Canada \\ ${ }^{3}$ Department of Earth and Environmental Sciences, Università degli Studi di Milano-Bicocca, Milan, Italy \\ ${ }^{4}$ Direction Générale de L’Environnement, Etat de Vaud, Lausanne, Switzerland \\ a now at: Geological Survey of Norway (NGU), Trondheim, Norway
}

Correspondence to: Pierrick Nicolet (pierrick.nicolet@alumnil.unil.ch)

Received: 4 November 2015 - Published in Nat. Hazards Earth Syst. Sci. Discuss.: 7 December 2015

Revised: 6 April 2016 - Accepted: 7 April 2016 - Published: 19 April 2016

\begin{abstract}
When calculating the risk of railway or road users of being killed by a natural hazard, one has to calculate a temporal spatial probability, i.e. the probability of a vehicle being in the path of the falling mass when the mass falls, or the expected number of affected vehicles in case such of an event. To calculate this, different methods are used in the literature, and, most of the time, they consider only the dimensions of the falling mass or the dimensions of the vehicles. Some authors do however consider both dimensions at the same time, and the use of their approach is recommended. Finally, a method considering an impact on the front of the vehicle is discussed.
\end{abstract}

\section{Introduction}

Natural hazards impacting on transportation corridors can cause traffic disruption, with direct and indirect economic consequences, and affect the users by direct impact on vehicles (hereafter refereed to as direct impact) or by impact of the user with deposited material.

When the indirect consequences (e.g. economical cost of the road closure) are taken into account, they generally largely outweigh the direct consequences. However, indirect consequences have no influence on the individual risk, which is often used as an acceptability criterion (e.g. Ho and Ko, 2009). Therefore, the impact of vehicles with falling or deposited material is worth attention. On the other hand, ac- cording to Pantelidis (2011), direct impact of a landslide on a moving vehicle is by far less likely than the impact of a vehicle with the landslide material deposited on the road. Nevertheless, using an inappropriate formulation to calculate the direct impact probability might still have a noticeable effect on the total risk assessment.

This paper reviews the approaches used to calculate the direct impact probability given that an event occurs. This is usually called temporal spatial probability (e.g. Fell et al., 2005, 2008; Ferlisi et al., 2012; Corominas and Mavrouli, 2013), although, depending on the hypothesis and formulation, it is expressed as an expected number of vehicles rather than a formal probability. It has to be mentioned that some methods also consider traffic jam situations, or account for the possibility of a warning system or for the driver to see the event in advance and to respond by braking. These situations are however beyond the scope of this article, where we concentrate on the category named "impact of a falling rock on a moving vehicle" by Bunce et al. (1997), keeping in mind that the calculation applies also to other falling or flowing material such as for debris flow or snow avalanches. For this review, the approaches are divided into three categories, namely, neglecting the event dimension (Sect. 2.1), neglecting the vehicle dimension (Sect. 2.2) and, finally, taking both dimensions into account (Sect. 2.3). 


\section{Temporal spatial probability of moving vehicles}

\subsection{Approaches neglecting the events dimension}

Most of the quantitative risk analyses for moving vehicles published in the literature concern rockfalls. To calculate the probability of a falling block hitting a car or a train, Eq. (1) is generally used (e.g. Bunce et al., 1997; Fell et al., 2005; Ferlisi et al., 2012; Mignelli et al., 2012; Corominas and Mavrouli, 2013; Wang et al., 2014; Macciotta et al., 2015):

$P_{\mathrm{ST}}=\frac{f_{\mathrm{V}} \times L_{\mathrm{V}}}{v_{\mathrm{V}}}$,

where (correspondence of the variables names used in this paper with those adopted in some of the cited works can be found in Appendix B)

- $P_{\mathrm{ST}}$ is the temporal spatial probability of a vehicle being in the path of the rock when it falls, neglecting the rock dimensions and considering a single lane with no vehicle overlap;

- $f_{\mathrm{V}}$ is the traffic density expressed in number of vehicles per time unit (e.g. average annual daily traffic, with proper unit conversion);

- $L_{\mathrm{V}}$ is the length of the vehicle;

$-v_{\mathrm{V}}$ is the mean vehicle velocity.

The aim of this equation is to calculate, as the block falls, the probability of a car being present at the instantaneous position of the block's centre of mass. The simplification of using the geometric centre of the block is valid only for $L_{\mathrm{V}}$ significantly larger than the size of the falling block, which is usually the case for trains, but might become an oversimplification for cars. In this case, $P_{\mathrm{ST}}$ is formally a probability, since a value of 1 would mean that cars move bumper to bumper.

The approach proposed by Peila and Guardini (2008) and used by Budetta et al. (2015) falls in the same category, although it takes into account the length of the hazard zone and the vehicle length. However, if we multiply their spatial probability by their temporal probability and by the vehicle frequency, we obtain

$\frac{L_{\mathrm{V}}}{L_{\mathrm{H}}} \times \frac{L_{\mathrm{H}}}{v_{\mathrm{V}}} \times f_{\mathrm{V}}=\frac{L_{\mathrm{V}} \times f_{\mathrm{V}}}{v_{\mathrm{V}}}$,

where $L_{\mathrm{H}}$ is the length of road included in the hazard zone. The simplification is then similar to Eq. (1). It has to be noted that Peila and Guardini (2008) use a binomial distribution to calculate the probability of one or more impacts, using the rockfall frequency as the number of experiments, and the spatial probability as the probability of success. We neglected this transformation here in order to keep the rockfall frequency out of the calculation, but the general idea is the same. This method is modified from Crosta et al. (2001).

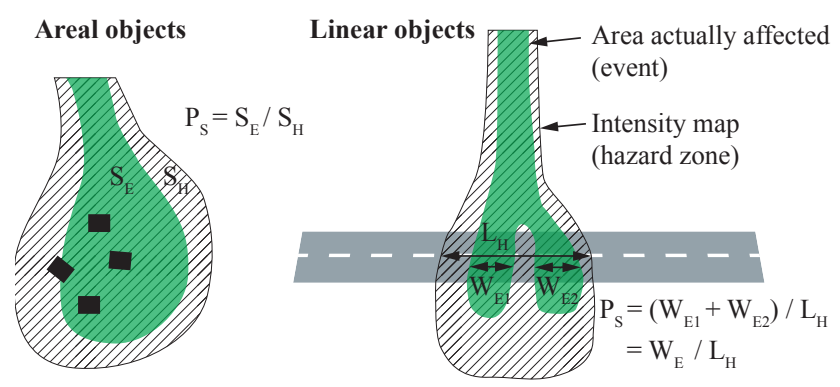

Figure 1. Calculation of the spatial occurrence probability $\left(P_{\mathrm{S}}\right)$ as used in the Swiss methodology. This probability corresponds to the proportion defined in the hazard map which is actually affected in the case of an event (left panel), or to the proportion of the length which is affected (modified from Bründl et al., 2015).

\subsection{Approaches neglecting the vehicle dimension}

In the following, we present two examples of methods neglecting the vehicle dimension: one is applied in Switzerland and the other is known as the average vehicle risk method.

\subsubsection{Approach used in Switzerland}

Risk analysis in Switzerland has been standardised by the requirement for the regional authorities to produce hazard maps (Raetzo et al., 2002), and by the attribution of subsidies for protective measures based on standardised costbenefit analyses using intensity maps prepared during the procedure of hazard mapping (Bründl et al., 2009). Systematic risk assessment is also performed for highways (Dorren et al., 2009) and for railways (Bründl et al., 2012).

The procedure used to design hazard maps consists in establishing scenarios for three different return periods, namely 30,100 and 300 years. The return period is defined for the source area, and intensity maps are built for each scenario, in order to identify the spatial distribution of the potential intensities. The conditional probability of the source material reaching any downslope location is considered only in a Boolean way, which means that the entire endangered area is considered as having the same probability of being affected. The three intensity maps are then combined to build the hazard, keeping the highest hazard level obtained by plotting the intensity-frequency combinations in a matrix. This last step is performed for land-use planning, but when it comes to risk analysis, intensity maps are used. Since intensity maps are characterised by the return period of the source and the total extension of the endangered area (generally considered as being equiprobable, which simplifies the calculation), the concept of spatial occurrence probability is introduced. This parameter aims to calculate the proportion of the area defined in the intensity map (or of the length if the object at risk is linear), which is actually affected in the case of an event (Fig. 1), or, roughly, the probability of a given location being affected in the scenario. 
Risk is then calculated for each scenario - before being summed to obtain the total risk - using the following formula (modified from Bründl et al., 2009):

$R=f \times P_{\mathrm{S}} \times P_{\mathrm{ST}}^{*} \times N_{\mathrm{P}} \times \lambda$,

where $f$ is the frequency of the scenario; $P_{\mathrm{S}}$ is the spatial occurrence probability, which is defined in Eq. (4); $P_{\mathrm{ST}}^{*}$ is the temporal spatial term, i.e. the number of expected cars in the portion of the road included in the hazard map (of length $L_{\mathrm{H}}$ ), and is defined in Eq. (5); $N_{\mathrm{P}}$ is the mean number of persons per vehicle and $\lambda$ is their vulnerability.

The spatial occurrence probability of the event is then

$P_{\mathrm{S}}=\frac{W_{\mathrm{E}}}{L_{\mathrm{H}}}$

with $W_{\mathrm{E}}$ being the actual width of the event on the road (i.e. the length of the road actually affected by the event) and $L_{\mathrm{H}}$ the length of the road included in the intensity map (i.e. the hazard zone, Fig. 1). The temporal spatial term is given by

$P_{\mathrm{ST}}^{*}=\frac{f_{\mathrm{V}} \times L_{\mathrm{H}}}{v_{\mathrm{V}}}$.

Multiplying Eq. (5) by (4), we can rewrite the temporal spatial term as follows:

$P_{\mathrm{ST}}=P_{\mathrm{ST}}^{*} \times P_{\mathrm{S}}=\frac{f_{\mathrm{V}} \times W_{\mathrm{E}}}{v_{\mathrm{V}}}$,

which represents the probability of the geometric centre of a moving vehicle being located in the section covered by the event $\left(W_{\mathrm{E}}\right)$. This approach is then valid only for $W_{\mathrm{E}}$ much larger than $L_{\mathrm{V}}$. However, this is often not the case since rockfalls (with small $W_{\mathrm{E}}$ ) are often a problem along roads or railways. Few technical papers in the literature use this approach (e.g. Dorren et al., 2009; Voumard et al., 2013, as a comparison with the risk that they calculate using a traffic simulator), but it is commonly used in practice. Zischg et al. (2005) use this formulation for snow avalanches impacting cars, which, in this case, is an acceptable simplification since $W_{\mathrm{E}}$ is generally large for snow avalanches.

With this approach, $P_{\mathrm{ST}}^{*}$ and $P_{\mathrm{ST}}$ are formally not probabilities, since several cars can be in the affected section simultaneously. It is indeed the expected number of affected cars.

\subsubsection{The average vehicle risk method}

A similar approach, neglecting the dimension of the vehicle, is the average vehicle risk (AVR) method used in the Rockfall Hazard Rating System (RHRS) (Pierson and Van Vickle, 1993; Budetta, 2002, 2004; Pierson, 2012). Although the RHRS is not intended to quantitatively assess the risk, the AVR criterion corresponds to a temporal spatial probability and is calculated as follows:

$P_{\mathrm{ST}}=\frac{f_{\mathrm{V}} \times L_{\mathrm{H}}}{v_{\mathrm{V}}}$, where $P_{\mathrm{ST}}$ corresponds to the variable AVR of the original methodology, except that it is not expressed here in percent. This method uses $L_{\mathrm{H}}$, which is the length of the hazard section (slope length in the original methodology), and neglects both the the vehicle dimension $\left(L_{\mathrm{V}}\right)$ and the event dimension $\left(W_{\mathrm{E}}\right)$. In this formulation, $P_{\mathrm{ST}}$ often takes a value above 1 , meaning that on average, more than one car is expected in the studied section.

Although this method is mostly used as an index rather than as a quantity, its use might lead to inexact results. Indeed, in Pierson and Van Vickle (1993) and Budetta (2004), the rating includes a frequency, which, for similar susceptibilities, is dependent on the considered slope length. At the same time, $P_{\mathrm{ST}}$ also reflects the slope length, which means that this parameter is considered twice in the classification. On the other hand, Ferlisi et al. (2012) modified the RHRS by using a frequency normalised to a unit slope length, which means that the section length is reflected only in $P_{\mathrm{ST}}$, which is then coherent.

\subsection{Approaches using both dimensions}

\subsubsection{Methods considering an impact on the side of the vehicle}

Few authors in the literature use both event size and vehicle length for a more complete risk assessment. Hantz (2011) uses a risk calculation, where the block size varies according to a power law, and the target dimension is set to $0.5 \mathrm{~m}$, corresponding to a hiker's "length". Michoud et al. (2012) also use the dimensions of the cars $(4 \mathrm{~m})$ and of the falling rocks. Borter (1999), in the original Swiss risk methodology, takes into account both the dimension of the falling mass and the length of the vehicle when estimating the risk for a train. This approach has been integrated recently in the official risk calculator EconoMe for trains traffic (Bründl et al., 2015), but the approach presented in Sect. 2.2.1 is still used for road traffic. This approach has also been presented by Hazzard (1998, p. 185). In these studies, the temporal spatial probability is calculated as follows:

$P_{\mathrm{ST}}=\frac{f_{\mathrm{V}} \times\left(W_{\mathrm{E}}+L_{\mathrm{V}}\right)}{v_{\mathrm{V}}}$.

The reason for the addition of $W_{\mathrm{E}}$ and $L_{\mathrm{V}}$ is illustrated in Fig. 2. $P_{\mathrm{ST}}$ is then independent of the length of the hazard area $L_{\mathrm{H}}$. It has to be mentioned that this equation will give inexact results in the case of a multiple path event, as the one presented in Fig. 1. Indeed, to be exact, the vehicle length should be added to the width of every path, which is not the case if the total width of the event is used. Cloutier (2014) also uses the two dimensions, but the equation differs by considering, in addition, the braking time and the time since the last clearance (to account for the impact of deposited material), which is beyond the scope of this review. 


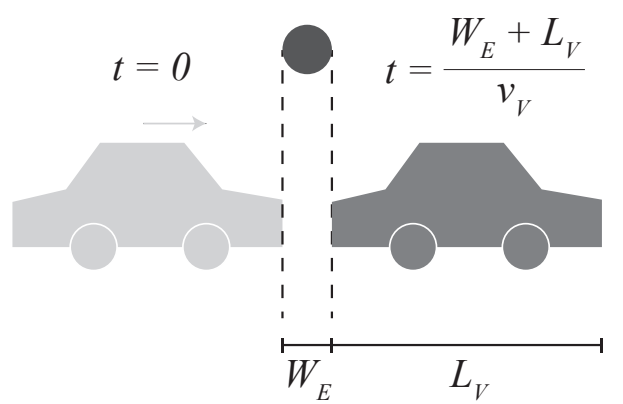

Figure 2. Temporal spatial probability considering both vehicle and event size. Every vehicle located between the left and the right position will be affected by the rockfall, which means that the temporal spatial probability will depend on the time needed to travel the distance $W_{\mathrm{E}}+L_{\mathrm{V}}$, as denoted in Eq. (8). Another way to see this is that a block will affect a car if its centre falls closer to $(1 / 2) W_{\mathrm{E}}$ in front or behind the car.

In addition, Borter (1999) proposes calculating the number of affected people on a train using the length of the event and the total number of passengers on the train $\left(N_{\mathrm{P}}^{\text {total }}\right)$ :

$N_{\mathrm{P}}^{\text {affected }}=\frac{N_{\mathrm{P}}^{\text {total }} \times W_{\mathrm{E}}}{L_{\mathrm{V}}}$.

$N_{\mathrm{P}}^{\text {affected }}$ then replaces $N_{\mathrm{P}}$ in the risk calculation (Eq. 3). Indeed, for long vehicles, many passengers might be located in a section of the vehicle that is not impacted and are therefore not expected to be affected. The passengers' "length" could also be added to the event's width in this equation, similarly to the addition of the event's width to the vehicle's length in $P_{\mathrm{ST}}$ (Eq. 8) or to the hiker's length in Hantz (2011), to account for the fact that a passenger with a geometric centre close to the path of the falling mass could actually be partly on its path. This is however a detail with respect to the fact that this last equation does not take the potential derailment of the train into account (see Cloutier, 2014), which could affect the passengers on a section of the train longer than the section directly affected by the falling material.

\subsubsection{Methods considering an impact on the side and front of the vehicle}

The most complete method is probably the one proposed by Roberds (2005), who uses a complex conditional probability model. The part of the model concerning the direct impact probability consists in calculating the probability of a falling mass passing between uniformly spaced vehicles, and taking its complement to 1 . The calculation is done as follows:

$P_{\mathrm{ST}}=1-\frac{\left[L_{\mathrm{S}}-\left(L_{\mathrm{E}}+W_{\mathrm{V}}\right) \frac{v_{\mathrm{V}}}{v_{\mathrm{E}}}\right]-W_{\mathrm{E}}}{L_{\mathrm{S}}+L_{\mathrm{V}}}$,

where the vehicle $\mathrm{V}$ is characterised by a length $L_{\mathrm{V}}$, a width $W_{\mathrm{V}}$ and a velocity $v_{\mathrm{V}}$, while the falling mass is characterised

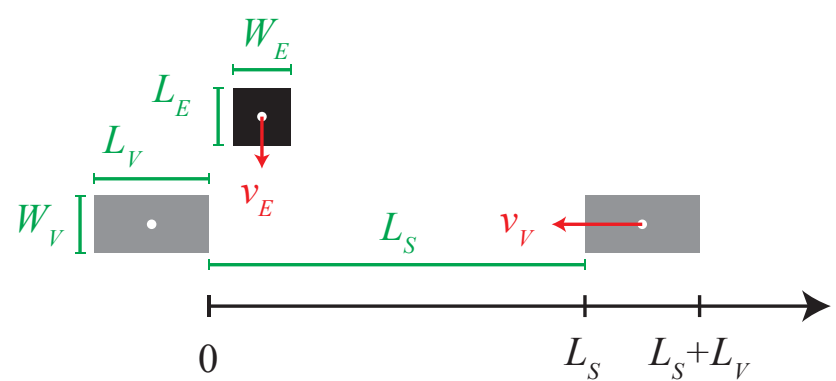

Figure 3. Parameters of the cars (in grey) and the falling mass (in black) used for the calculations in Roberds' (2005) method. The origin of the abscissa axis is located at the rear of the front car. The length of the hazard zone is not indicated in this figure because it does not influence the calculation.

by a length $L_{\mathrm{E}}$ (perpendicular to the vehicle length), a width $W_{\mathrm{E}}$ and a velocity $v_{\mathrm{E}} . L_{\mathrm{S}}$ is the spacing between the vehicles and depends on the traffic density (Fig. 3). With this approach, the possibility for a car to collide frontally with an event occurring is taken into account (see Appendix A). The limitation of this method consists in considering that vehicles are uniformly spaced, but the impact probability is actually higher if they are not. Indeed, since $L_{\mathrm{S}}$ is present in the numerator and in the denominator, and since the numerator is always smaller than the denominator, a negative change in $L_{\mathrm{S}}$ (denoted $\Delta L_{\mathrm{S}}$ ) will result in a positive change in $P_{\mathrm{ST}}$ (denoted $\Delta P_{\mathrm{ST}}$ ) larger, in absolute values, than the $\Delta P_{\mathrm{ST}}$ resulting from an equivalent positive $\Delta L_{\mathrm{S}}$. Therefore, on average, $P_{\mathrm{ST}}$ with $L_{\mathrm{S}}$ varying around a mean $\bar{L}_{\mathrm{S}}$ will be larger than $P_{\mathrm{ST}}$ resulting from a constant $L_{\mathrm{S}}=\bar{L}_{\mathrm{S}}$.

\section{Synthetic examples}

Two examples of risk calculation using the different methods are given in Tables 1 and 2, respectively, for cars and for trains. The risk is calculated only for direct impacts. In the case of rockfalls affecting cars, the temporal spatial probability using Eq. (1), which is widely used in the literature, is around $18 \%$ lower than if both dimensions are used (Eq. 8) and $43 \%$ lower than considering an impact on the side and front (Eq. 10). Neglecting the size of the vehicle (Eq. 6) gives a $P_{\mathrm{ST}}$ farther from the expected value (obtained with Eq. 10). For cars, the difference in $P_{\mathrm{ST}}$ is directly reflected on the risk estimation.

When it comes to trains, the temporal spatial probability is largely inferior with Eq. (6). However, if $N_{\mathrm{P}}^{\text {affected }}$ is used when needed, the risk estimations are quite similar to the different methods. We consider that $N_{\mathrm{P}}^{\text {affected }}$ is needed whenever $L_{\mathrm{V}}$ is taken into account. Indeed, if $L_{\mathrm{V}}$ is not used (Eq. 6), $P_{\mathrm{ST}}$ considers the vehicle as being dimensionless. Therefore, $P_{\mathrm{ST}}$ in Eq. (6) is somehow already the probability of a train user being affected. 
Table 1. Example of risk calculation for car passengers (direct impact only). Parameters are shown only when used in the calculation. In addition to the parameters presented in the text, the risk is calculated using the vulnerability of the car passengers $(V)$ and the hazard frequency $(H)$.

\begin{tabular}{llllll}
\hline Parameter & Dimension & Eq. (1) & Eq. (6) & Eq. (8) & Eq. (10) \\
\hline$f_{\mathrm{V}}$ & $\left(\right.$ vehicles day $\left.^{-1}\right)$ & 5000 & 5000 & 5000 & 5000 \\
$L_{\mathrm{V}}$ & $(\mathrm{m})$ & 4.5 & - & 4.5 & 4.5 \\
$W_{\mathrm{V}}$ & $(\mathrm{m})$ & - & - & - & 2 \\
$v_{\mathrm{V}}$ & $\left(\mathrm{km} \mathrm{h}^{-1}\right)$ & 80 & 80 & 80 & 80 \\
$W_{\mathrm{E}}$ & $(\mathrm{m})$ & - & 1 & 1 & 1 \\
$L_{\mathrm{E}}$ & $(\mathrm{m})$ & - & - & - & 1 \\
$v_{\mathrm{E}}$ & $\left(\mathrm{km} \mathrm{h}^{-1}\right)$ & - & - & - & 100 \\
$L_{\mathrm{S}}$ & $(\mathrm{m})$ & - & - & - & 379.5 \\
\hline$P_{\mathrm{ST}}$ & $(-)$ & $1.17 \times 10^{-2}$ & $2.60 \times 10^{-3}$ & $1.43 \times 10^{-2}$ & $2.06 \times 10^{-2}$ \\
\hline$H$ & $\left(\mathrm{yr}^{-1}\right)$ & 0.1 & 0.1 & 0.1 & 0.1 \\
$V$ & $(-)$ & 0.5 & 0.5 & 0.5 & 0.5 \\
$N_{\mathrm{P}}$ & $(\text { persons })_{R}$ & 1.76 & 1.76 & 1.76 & 1.76 \\
$R$ & $\left(\right.$ persons $\left.\mathrm{yr}^{-1}\right)$ & $1.03 \times 10^{-3}$ & $2.29 \times 10^{-4}$ & $1.26 \times 10^{-3}$ & $1.81 \times 10^{-3}$ \\
\hline
\end{tabular}

Table 2. Example of risk calculation for train passengers (direct impact only). Parameters are shown only when used in the calculation. In addition to the parameters presented in the text, the risk is calculated using the vulnerability of the car passengers $(V)$ and the hazard frequency $(H)$.

\begin{tabular}{|c|c|c|c|c|c|}
\hline Parameter & Dimension & Eq. (1) & Eq. (6) & Eq. (8) & Eq. (10) \\
\hline$f_{\mathrm{V}}$ & $\left(\right.$ vehicles day $\left.^{-1}\right)$ & 30 & 30 & 30 & 30 \\
\hline$L_{\mathrm{V}}$ & (m) & 200 & - & 200 & 200 \\
\hline$W_{\mathrm{V}}$ & (m) & - & - & - & 2 \\
\hline$v_{\mathrm{V}}$ & $\left(\mathrm{km} \mathrm{h}^{-1}\right)$ & 150 & 150 & 150 & 150 \\
\hline$W_{\mathrm{E}}$ & (m) & - & 1 & 1 & 1 \\
\hline$L_{\mathrm{E}}$ & (m) & - & - & - & 1 \\
\hline$v_{\mathrm{E}}$ & $\left(\mathrm{km} \mathrm{h}^{-1}\right)$ & - & - & - & 100 \\
\hline$L_{\mathrm{S}}$ & $(\mathrm{m})$ & - & - & - & $1.20 \times 10^{5}$ \\
\hline$P_{\mathrm{ST}}$ & $(-)$ & $1.67 \times 10^{-3}$ & $8.33 \times 10^{-6}$ & $1.68 \times 10^{-3}$ & $1.71 \times 10^{-3}$ \\
\hline$H$ & $\left(\mathrm{yr}^{-1}\right)$ & 0.1 & 0.1 & 0.1 & 0.1 \\
\hline$V$ & $(-)$ & 0.5 & 0.5 & 0.5 & 0.5 \\
\hline$N_{\mathrm{P}}^{\text {total }}$ & (persons) & 175 & 175 & 175 & 175 \\
\hline$N_{\mathrm{P}}^{\text {affected }}$ & (persons) & 0.9 & - & 0.9 & 0.9 \\
\hline$R$ & (persons $\mathrm{yr}^{-1}$ ) & $7.29 \times 10^{-5}$ & $7.29 \times 10^{-5}$ & $7.33 \times 10^{-5}$ & $7.49 \times 10^{-5}$ \\
\hline
\end{tabular}




\section{Discussion and conclusions}

Although risk resulting from direct impact of the event with a moving vehicle is generally lower than the risk of a moving vehicle hitting debris deposited on its way, it is not negligible. As a consequence, neglecting the dimension of the event or the dimension of the vehicle when calculating the direct impact risk might lead to an inexact result if the neglected dimension is not significantly lower than the other one. Therefore, we recommend using Eq. (8) rather than Eqs. (1) and (6), in order to avoid significant errors. Although, as shown in Table 2, the difference in risk evaluation for the passengers might be reduced to a reasonable level by using a suitable method to calculate the number of affected people, an incorrect $P_{\mathrm{ST}}$ could also affect other consequence scenarios, such as train derailment. Indeed, if $P_{\mathrm{ST}}$ is used to calculate the probability of a road or railway closure after a vehicle has been hit by a falling mass (disregarding whether a passenger has been affected or not), then the method used to calculate $P_{\mathrm{ST}}$ really matters (considering that the closure will be longer if a train has to be removed from the track than if the track only needs to be cleared of fallen material). In addition, the calculation of $N_{\mathrm{P}}^{\text {affected }}$ (Eq. 9) highlights the fact that the rest of the risk calculation has to be coherent with the calculation of $P_{\mathrm{ST}}$. Indeed, if $P_{\mathrm{ST}}$ is the probability of a vehicle being hit by a falling mass, since some passengers might be in a part of the train that is not affected, then whether (1) the vulnerability is the conditional probability of a passenger dying if any part of the vehicle is affected (and might therefore be very low), or (2) the vulnerability is the conditional probability of a passenger dying if the part of the vehicle where he or she is located is affected, as a consequence, the number of people $N_{\text {P }}$ should be computed with Eq. (9).
More in-depth analysis could be performed using the approach presented in Eq. (10), which takes into account the possibility of a frontal impact with a moving vehicle. However, this approach needs many parameters that are not always easy to assess, and the results are different if the spacing between the cars is not constant. Moreover, this latter method considers the impact of a vehicle with a falling mass crossing the road, but, in many situations, the falling mass will stop on the road or on the railway, causing much higher risk. This is particularly critical for trains because they have limited chances of avoiding contact if rockfall debris is on the rail track and if the train operators are not informed of the situation ahead. Indeed, trains have large stopping distances (particularly freight trains) and cannot manoeuvre to avoid debris.

To conclude, it is important to understand that the present communication only aims at discussing the spatial interaction of two moving objects, namely the falling mass and the vehicle, and that other scenarios, such as the impact with deposited material or the economic consequences of a road or railway closure, should be analysed in addition if applicable. 


\section{Appendix A: Demonstration of Roberds' (2005) approach}

Consider a mass of debris of length $L_{\mathrm{E}}$ and width $W_{\mathrm{E}}$ falling on a road with a velocity $v_{\mathrm{E}}$ (Fig. 3). On the road, vehicles of length $L_{\mathrm{V}}$ and width $W_{\mathrm{V}}$ are moving with a velocity $v_{\mathrm{V}}$, and are separated from each other by a constant distance $L_{\mathrm{S}}$. The time needed by the falling mass to completely cross the vehicle's trajectory is

$t=\frac{W_{\mathrm{V}}+L_{\mathrm{E}}}{v_{\mathrm{E}}}$.

During this time, the vehicles will move forward by the distance:

$d=v_{\mathrm{V}} \times t=v_{\mathrm{V}} \times \frac{\left(W_{\mathrm{V}}+L_{\mathrm{E}}\right)}{v_{\mathrm{E}}}=\left(W_{\mathrm{V}}+L_{\mathrm{E}}\right) \times \frac{v_{\mathrm{V}}}{v_{\mathrm{E}}}$.

If we consider that the vehicles in Fig. 3 are static, the leftmost abscissa where the moving mass can cross the road equals

$x_{0}=\frac{1}{2} W_{\mathrm{E}}$.

This coordinate equals half of the debris width, since the reference system of the debris is located at its centre.

With static vehicles, the rightmost abscissa $x_{1}$ would be $L_{\mathrm{S}}$ minus half of the width of the falling mass, similarly to $x_{0}$. However, since the vehicles are moving, the distance travelled by the car during the time spent by the falling mass crossing the road $(d)$ needs to be removed.

$$
\begin{aligned}
x_{1} & =L_{\mathrm{S}}-d-\frac{1}{2} W_{\mathrm{E}} \\
& =L_{\mathrm{S}}-\left(\left(W_{\mathrm{V}}+L_{\mathrm{E}}\right) \times \frac{v_{\mathrm{V}}}{v_{\mathrm{E}}}\right)-\frac{1}{2} W_{\mathrm{E}}
\end{aligned}
$$

Therefore, the distance on the abscissa which is available for the block to cross without affecting a car is

$$
\begin{aligned}
\Delta x & =x_{1}-x_{0} \\
& =L_{\mathrm{S}}-\left(\left(W_{\mathrm{V}}+L_{\mathrm{E}}\right) \times \frac{v_{\mathrm{V}}}{v_{\mathrm{E}}}\right)-\frac{1}{2} W_{\mathrm{E}}-\frac{1}{2} W_{\mathrm{E}} \\
& =L_{\mathrm{S}}-\left(\left(W_{\mathrm{V}}+L_{\mathrm{E}}\right) \times \frac{v_{\mathrm{V}}}{v_{\mathrm{E}}}\right)-W_{\mathrm{E}} .
\end{aligned}
$$

The probability of the block crossing the road without affecting a car $P_{\overline{\mathrm{ST}}}$ is the proportion of favourable abscissa $\Delta x$ compared to the total distance $L_{\mathrm{S}}+L_{\mathrm{V}}$. Therefore, the probability of the block affecting a car $P_{\mathrm{ST}}$ is the complement of $P_{\overline{\mathrm{ST}}}$ :

$$
\begin{aligned}
P_{\mathrm{ST}} & =1-P_{\overline{\mathrm{ST}}} \\
& =1-\frac{\left[L_{\mathrm{S}}-\left(L_{\mathrm{E}}+W_{\mathrm{V}}\right) \frac{v_{\mathrm{V}}}{v_{\mathrm{E}}}\right]-W_{\mathrm{E}}}{L_{\mathrm{S}}+L_{\mathrm{V}}} .
\end{aligned}
$$




\section{Appendix B: Variable names}

A table of correspondence of the variable names in the literature is given in Table B1.

Table B1. Correspondence of selected variables names used in this paper with the original methodologies. $P_{\mathrm{ST}}$ is the temporal spatial probability, $f_{\mathrm{V}}$ the vehicle frequency, $L_{\mathrm{V}}$ the length of the vehicles, $v_{\mathrm{V}}$ their velocity, $W_{\mathrm{E}}$ the width of the event, $P_{\mathrm{S}}$ the spatial occurrence probability of the event in the Swiss methodology, $P_{\mathrm{ST}}^{*}$ is the temporal spatial term of the Swiss methodology and $L_{\mathrm{H}}$ the length of the hazard zone

\begin{tabular}{|c|c|c|c|c|c|c|c|c|}
\hline & $\begin{array}{l}\text { Name in this paper } \\
P_{\mathrm{ST}}\end{array}$ & $f_{\mathrm{V}^{\mathrm{a}}}$ & $L_{\mathrm{V}}$ & $v_{\mathrm{V}}$ & $W_{\mathrm{E}}$ & $P_{\mathrm{S}}$ & $P_{\mathrm{ST}}^{*}$ & $L_{\mathrm{H}}$ \\
\hline Bunce et al. (1997) & $P(S: H)$ & $N_{\mathrm{V}}$ & $L_{\mathrm{V}}$ & $V_{\mathrm{V}}$ & - & - & - & - \\
\hline Dorren et al. (2009) & $\mathrm{Nc}$ & AHT & - & Vmax & slide width & Pso & - & - \\
\hline Bründl et al. (2009) & - & MDT & - & $v$ & - & $p(s)$ & $p(\mathrm{et})$ & $g$ \\
\hline Pierson (1991) & AVR & ADT & - & posted speed limit & - & - & - & slope length \\
\hline Borter (1999, p. 76) & $p_{\operatorname{Pr}}$ & $F_{\mathrm{Z}}$ & $L_{\mathrm{Z}}$ & $v$ & $g$ & $p_{\mathrm{rA}}$ & - & - \\
\hline Roberds (2005) & $P 4_{1}$ & $\lambda V$ & $V_{\mathrm{L}}$ & $V_{\mathrm{v}}$ & $D_{\mathrm{W}}$ & - & - & - \\
\hline Peila and Guardini (2008) & $P(A)$ tot $^{\mathrm{b}}$ & $N_{\mathrm{V} / \mathrm{a}}$ & $L_{\mathrm{V}}$ & $V_{\mathrm{V}}$ & - & - & - & $L_{\mathrm{p}}$ \\
\hline
\end{tabular}

a The correction factors applied to $f_{\mathrm{V}}$ are not considered here.

$\mathrm{b}$ The original variable considers the number of falling blocks in addition. 
Acknowledgements. The authors would like to thank Bernard Loup (Federal Office for the Environment, Switzerland) and Clément Michoud (terr@num, Switzerland) for the discussion on their respective methodologies, as well as Michael Bründl and Rainer Poisel for their relevant reviews.

Edited by: M. Keiler

\section{References}

Borter, P.: Risikoanalyse bei gravitativen Naturgefahren: Methode, Umwelt-Materialien 107/I, Bundesamt für Umwelt, Wald und Landschaft (BUWAL), Bern, 1999.

Bründl, M., Romang, H. E., Bischof, N., and Rheinberger, C. M.: The risk concept and its application in natural hazard risk management in Switzerland, Nat. Hazards Earth Syst. Sci., 9, 801813, doi:10.5194/nhess-9-801-2009, 2009.

Bründl, M., Winkler, C., and Baumann, R.: "EconoMe-Railway" a new calculation method and tool for comparing the effectiveness and the cost-efficiency of protective measures along railways, in: 12th Congress INTERPRAEVENT 2012, Grenoble, France, 2012.

Bründl, M., Ettlin, L., Burkard, A., Oggier, N., Dolf, F., and Gutwein, P.: EconoMe: Wirksamkeit und Wirtschaftlichkeit von Schutzmassnahmen gegen Naturgefahren, Formelsammlung, Federal Office for the Environment (FOEN), Schweizerische Bundesbahnen (SBB), Bern, 2015.

Budetta, P.: Risk assessment from debris flows in pyroclastic deposits along a motorway, Italy, B. Eng. Geol. Environ., 61, 293301, doi:10.1007/s10064-002-0161-6, 2002.

Budetta, P.: Assessment of rockfall risk along roads, Nat. Hazards Earth Syst. Sci., 4, 71-81, doi:10.5194/nhess-4-71-2004, 2004.

Budetta, P., De Luca, C., and Nappi, M.: Quantitative rockfall risk assessment for an important road by means of the rockfall risk management (RO.MA.) method, B. Eng. Geol. Environ., 1-21, doi:10.1007/s10064-015-0798-6, 2015.

Bunce, C., Cruden, D., and Morgenstern, N.: Assessment of the hazard from rock fall on a highway, Can. Geotech. J., 34, 344-356, 1997.

Cloutier, C.: Évaluation du comportement cinétique et du risque associé aux glissements de terrain rocheux actifs à l'aide de mesures de surveillance: Le cas du glissement de Gascons, Gaspésie, Canada, $\mathrm{PhD}$ thesis, Université Laval, available at: http://www.theses.ulaval.ca/2014/30635/, last access: 30 November 2015, 2014.

Corominas, J. and Mavrouli, O.: Rockfall quantitative risk assessment, in: Rockfall Engineering, edited by: Lambert, S. and Nicot, F., John Wiley and Sons, Inc., Hoboken, 255-301, doi:10.1002/9781118601532.ch8, 2013.

Crosta, G., Frattini, P., and Sterlacchini, S.: Valutazione e gestione del rischio da frana, vol. 1 of Valutazione della pericolosit a e del rischio da frana in Lombardia, Regione Lombardia, Milano, 2001.

Dorren, L., Sandri, A., Raetzo, H., and Arnold, P.: Landslide risk mapping for the entire Swiss national road network, in: Landslide Processes: From Geomorphologic Mapping to Dynamic Modelling, edited by: Malet, J.-P., Remaître, A., and Bogaard, T., CERG, Utrecht University and University of Strasbourg, Stras- bourg, 6-7 February 2009, available at: http://eost.u-strasbg. fr/omiv/Landslide_Processes_Conference/Dorren_et_al.pdf (last access: 30 November 2015), 2009.

Fell, R., Ho, K. K. S., Lacasse, S., and Leroi, E.: A framework for landslide risk assessment and management, in: Landslide Risk Management, edited by: Hungr, O., Fell, R., Couture, R., and Eberhardt, E., Taylor and Francis Group, London, 3-26, 2005.

Fell, R., Corominas, J., Bonnard, C., Cascini, L., Leroi, E. and Savage, W. Z.: Guidelines for landslide susceptibility, hazard and risk zoning for land-use planning, Eng. Geol., 102, 85-98, 2008.

Ferlisi, S., Cascini, L., Corominas, J., and Matano, F.: Rockfall risk assessment to persons travelling in vehicles along a road: the case study of the Amalfi coastal road (southern Italy), Nat. Hazards, 62, 691-721, doi:10.1007/s11069-012-0102-z, 2012.

Hantz, D.: Quantitative assessment of diffuse rock fall hazard along a cliff foot, Nat. Hazards Earth Syst. Sci., 11, 1303-1309, doi:10.5194/nhess-11-1303-2011, 2011.

Hazzard, J.: Risk analysis of landslides affecting major transportation corridors in southwestern British Columbia, Master's thesis, University of British Columbia, available at: http://circle.ubc.ca/ handle/2429/8933 (last access: 30 November 2015), 1998.

Ho, K. and Ko, F.: Application of quantified risk analysis in landslide risk management practice: Hong Kong experience, Georisk, 3, 134-146, doi:10.1080/17499510902873074, 2009.

Macciotta, R., Martin, C. D., Morgenstern, N. R., and Cruden, D. M.: Quantitative risk assessment of slope hazards along a section of railway in the Canadian Cordillera - a methodology considering the uncertainty in the results, Landslides, 1-13, doi:10.1007/s10346-014-0551-4, 2015.

Michoud, C., Derron, M.-H., Horton, P., Jaboyedoff, M., Baillifard, F.-J., Loye, A., Nicolet, P., Pedrazzini, A., and Queyrel, A.: Rockfall hazard and risk assessments along roads at a regional scale: example in Swiss Alps, Nat. Hazards Earth Syst. Sci., 12, 615-629, doi:10.5194/nhess-12-615-2012, 2012.

Mignelli, C., Lo Russo, S., and Peila, D.: ROckfall risk MAnagement assessment: the RO.MA. approach, Nat. Hazards, 62, 1109-1123, doi:10.1007/s11069-012-0137-1, 2012.

Pantelidis, L.: A critical review of highway slope instability risk assessment systems, B. Eng. Geol. Environ., 70, 395-400, doi:10.1007/s10064-010-0328-5, 2011.

Peila, D. and Guardini, C.: Use of the event tree to assess the risk reduction obtained from rockfall protection devices, Nat. Hazards Earth Syst. Sci., 8, 1441-1450, doi:10.5194/nhess-8-1441-2008, 2008.

Pierson, L. A.: Rockfall Hazard Rating System, Tech. Rep. FHWAOR-GT-92-05, Oregon Department of Transportation, Salem, 1991.

Pierson, L. A.: Rockfall hazard rating system, in: Rockfall: Characterization and Control, edited by: Turner, A. K. and Schuster, R. L., Trans Res Board, Washington, D.C., 2012.

Pierson, L. A. and Van Vickle, R.: Rockfall Hazard Rating System - Participant's Manual, Final Report FHWA-SA-93-057, Federal Highway Administration, Phoenix, 1993.

Raetzo, H., Lateltin, O., Bollinger, D., and Tripet, J. P.: Hazard assessment in Switzerland - Codes of Practice for mass movements, B. Eng. Geol. Environ., 61, 263-268, 2002.

Roberds, W.: Estimating temporal and spatial variability and vulnerability, in: Landslide Risk Management, edited by: Hungr, O., 
Fell, R., Couture, R., and Eberhardt, E., Taylor and Francis, London, 129-157, 2005.

Voumard, J., Caspar, O., Derron, M.-H., and Jaboyedoff, M.: Dynamic risk simulation to assess natural hazards risk along roads, Nat. Hazards Earth Syst. Sci., 13, 2763-2777, doi:10.5194/nhess-13-2763-2013, 2013.

Wang, X., Frattini, P., Crosta, G., Zhang, L., Agliardi, F., Lari, S., and Yang, Z.: Uncertainty assessment in quantitative rockfall risk assessment, Landslides, 11, 711-722, doi:10.1007/s10346-0130447-8, 2014.
Zischg, A., Fuchs, S., Keiler, M., and Stötter, J.: Temporal variability of damage potential on roads as a conceptual contribution towards a short-term avalanche risk simulation, Nat. Hazards Earth Syst. Sci., 5, 235-242, doi:10.5194/nhess-5-235-2005, 2005. 